Florida International University FIU Digital Commons

$12-8-1994$

\title{
Increasing nurse's knowledge of neonatal pain assessment through inservice education program
}

Carol Beloff

Florida International University

DOI: $10.25148 /$ etd.FI14050487

Follow this and additional works at: https://digitalcommons.fiu.edu/etd

Part of the Nursing Commons

\section{Recommended Citation}

Beloff, Carol, "Increasing nurse's knowledge of neonatal pain assessment through inservice education program" (1994). FIU Electronic Theses and Dissertations. 1485.

https://digitalcommons.fiu.edu/etd/1485

This work is brought to you for free and open access by the University Graduate School at FIU Digital Commons. It has been accepted for inclusion in FIU Electronic Theses and Dissertations by an authorized administrator of FIU Digital Commons. For more information, please contact dcc@fiu.edu. 


\section{FLORIDA INTERNATIONAL UNIVERSITY \\ Miami, Florida}

\section{INCREASING NURSES KNOWLEDGE OF NEONATAL PAIN ASSESSMENT THROUGH INSERVICE EDUCATION PROGRAM}

A thesis submitted in partial satisfaction of the

requirements for the degree of

MASTER OF SCIENCE

IN

NURSING

by

Carol Beloff

1994 
To: Dr. JacquelynHartley

Acting Dean, School of Nursing

This thesis, written by Carol Beloff, and entitled INCREASING NURSES'

KNOWLEDGE OF NEONATAL PAIN ASSESSMENT THROUGH INSERVICE

EDUCATION PROGRAM, having been approved in respect to and style and intellectual content, is referred to you for judgement.

We have read this thesis and recommended that it be approved.

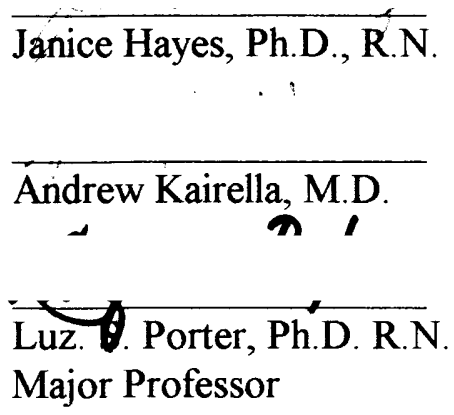

Date of Defense: December 8, 1994

The thesis of Carol Beloff is approved.

\author{
Jacquelyn Hartey, Ph.D. \\ Acting Dean, \\ Sphool of Nursing \\ Dr. Richard L. Campbell \\ Dean of Graduate Studies
}

Florida International University, 1994 
I dedicate this thesis to my husband Robert, and my children Alex and Samantha. Without their patience, understanding, support, and most of all love, the completion of this work would not have been possible. 


\section{ACKNOWLEDGEMENTS}

I wish to thank the members of my committee for their guidance, patience, and support. I also want to thank others who have been very helpful of my endeavors; my coworkers for their patience; my friends and family for their love.

A special thanks must go to my major professor Dr. Luz Porter; without her assistance this project would not have been completed. 


\begin{abstract}
OF THE THESIS
INCREASING NURSES' KNOWLEDGE OF NEONATAL PAIN

ASSESSMENT THROUGH INSERVICE EDUCATION PROGRAM.

by
\end{abstract}

Carol Beloff

Florida International University, 1994

Professor Luz Porter, Major Professor

Recognizing neonatal pain is a challenge for nurses working with newborns due to the complexity of the pain phenomenon. Pain is subjective, and infants lack the ability to communicate, and their pain is difficult to recognize. The purpose of this study is to determine the effectiveness of education on the NICU nurses' ability to assess neonatal pain. With a better understanding of pain theory and the effects of pain on the newborn the nurse will be better able to assess newborns with pain. Designed as a quasi-experimental one-group pretest and posttest study, the data was collected on a convenience sample of 49 registered nurses employed in the neonatal and special care nursery units at a Childrens Hospital in the Miami area. The nurses were surveyed on the assessment of neonatal pain using the General Information and Pain Sensitivity Questionnaire. After the initial survey, the nurses were inserviced on neonatal pain assessment using a one hour inservice education program. One week after the intervention the nurse was asked to complete the questionnaire again. Data analysis involved comparision of pre and post intervention findings using descriptive methods, $t$ test, correlation coefficients, and ANOVA, where 
applicable. Findings revealed a significant $(p=.006)$ increase in nurse's knowledge of neonatal pain assessment after completing the educational inservice when comparing the pre-test and post-test results. 


\section{TABLE OF CONTENTS}

CHAPTER

PAGE

I. Introduction

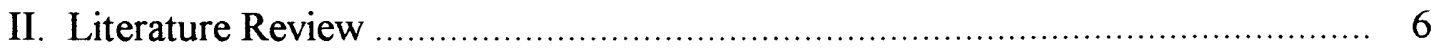

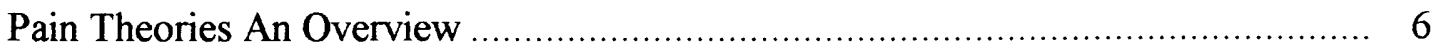

Nurses Assessment of Pain .............................................................. 8

Educative Measures Enhancing ......................................................... 11

Variables Affecting Pain Assessment................................................ 13

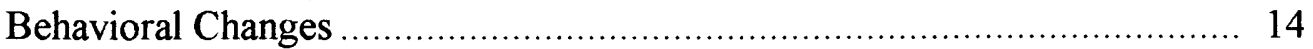

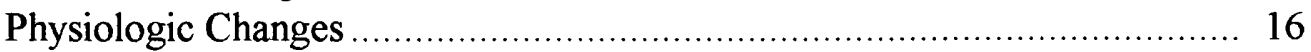

Application of Nursing Theories ...................................................... 17

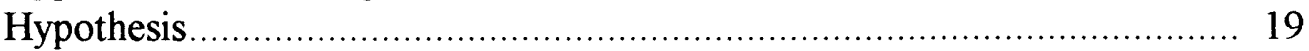

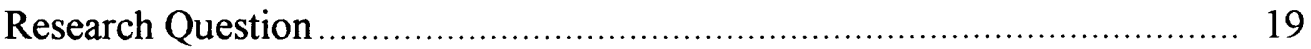

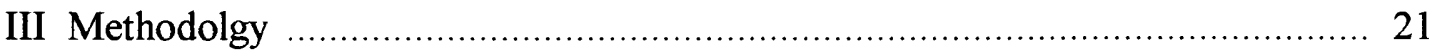

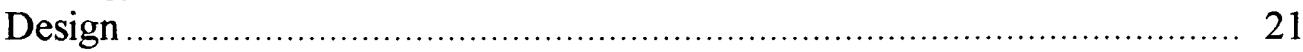

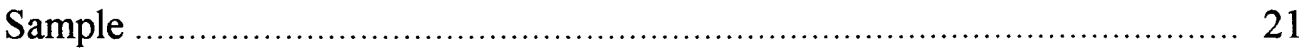

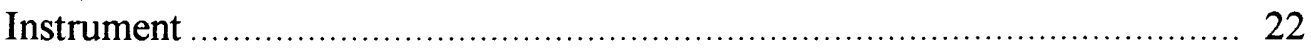

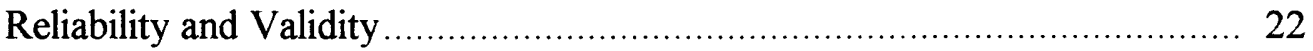

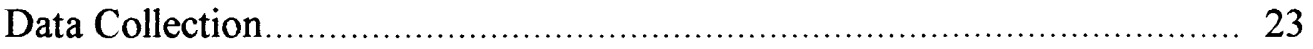

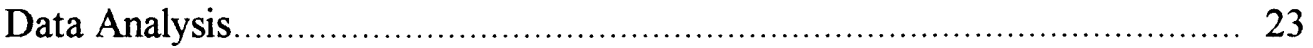

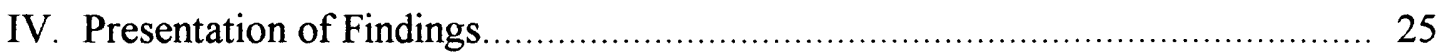

Characteristics of the Sample ............................................................ 25

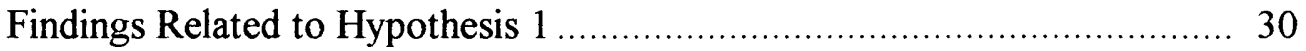

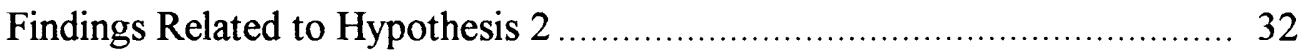

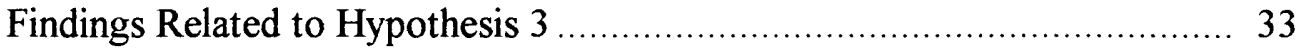

Findings Related to the Research Question......................................... 34

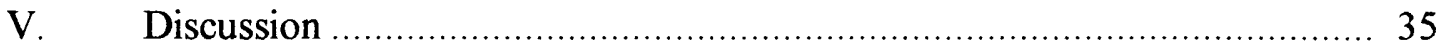

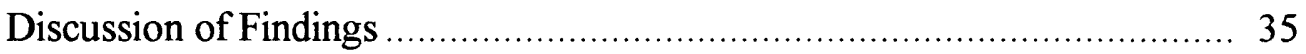

$\begin{array}{ll}\text { Summary } & 37\end{array}$

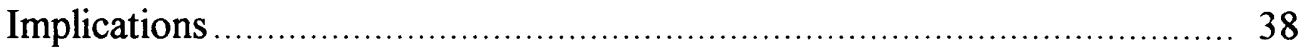

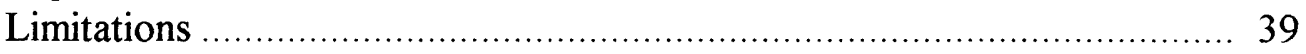

Recommendations for Future Studies .............................................. 39

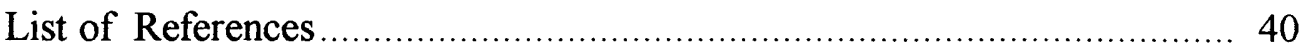

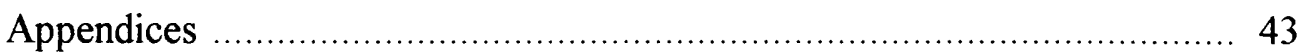




\section{LIST OF TABLES}

TABLE

PAGE

1 Frequency Distribution of the Sample by

Ethnicity and Religion

2 Frequency Distribution of the Sample by

Education and Marital Status

3 Frequency Distribution of the Sample by

Number and Age of Children.

$4 \quad$ Frequency Distribution of the Sample by

Setting

5 Proportion of Sample Who Had Taken Courses in Pain in Their Nursing Practice.

6 Summary of Paired T-Test Results

7 Relationship Between Nurses Educational Level and Nurses' Knowledge of Neonatal Pain Assessment

8 Relationship Between Total Years Taking Care of Holpitalized Infants, Years in Nursing with Knowledge of Neonatal Pain Assessment 


\section{LIST OF APPENDICES}

\section{APPENDIX}

1 Informed Consent for Nurses Assessment of

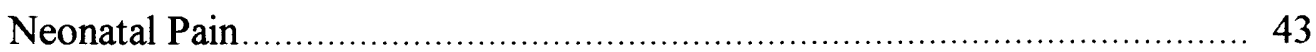

2 Neonatal Pain Assessment ................................................................. 45

3 General Information Questionnaire .................................................... 46

$4 \quad$ Pain Assessment Questionnaire ..................................................... 48

$5 \quad$ Graduate Studies Bulletin................................................................... 54 


\section{Chapter 1}

\section{Introduction}

Recognizing neonatal pain is a challenge to nurses working with newborns due to the complexity of the pain phenomenon. Pain is subjective, and infants lack the ability to communicate, thereby making their pain difficult to recognize. Lack of consistency in pain assessment and personal attitudes about pain have been identified as concerns in the Newborn Intensive Care Unit (NICU).

The belief that infants are incapable of experiencing pain is due to several misconceptions: the infant lacks pain receptors, there is a lack of myelination in the peripheral nerves, and the CNS is underdeveloped. Current research has changed these beliefs and has shown that infants do indeed feel pain.

The infant's nervous system is sufficiently mature by 20 weeks gestation to experience pain or nociception. Nociception is the detection of a painful stimulus in the peripheral nerve endings and the transmission of information from the site of painful stimulation to the brain (Johnson 1991).

Lack of myelination is used frequently to support the argument that preterm infants are not capable of pain perception. However even in adult peripheral nerves, nociceptive impulses are carried through unmyelinated and thinly myelinated fibers. Incomplete myelination merely implies slower conduction velocity in neonatal nerve tracts (Clancy \& Anand, 1992).

The accurate detection of pain is a prerequisite to providing maximally effective pain prevention and relief. The assessment of pain in the newborn is, therefore, one of the most important challenges facing newborn medicine today (Porter, 1989). 
Franck (1987) found a lack of consistency in attitudes and practices among staff nurses in NICUs with regard to infant pain and has reported that current practice regarding pain assessment and management is inadequate. Als (1986) has revealed that even in premature infants, developmental and medical outcomes could be improved by individualized nursing care emphasizing early pain and stress reduction.

\section{Purpose}

The purpose of this study is to determine the effectiveness of education on NICU nurse's ability to assess neonatal pain. With a better understanding of current pain theory, clarification of misconceptions about neonatal pain, and a better understanding of the effects of pain on the newborn, the nurse will be better able to assess newborns with pain.

\section{Problem Statement}

\section{General Problem:}

To what extent does a focused inservice education program enhance nurses' ability to assess pain in neonates?.

\section{Specific Problems}

1. To what extent does neonatal nursing experience enhance nurses' ability to assess pain in neonates?

2. To what extent does level of nursing education enhance nurses' ability to assess pain in the neonate?

3. To what extent do personal characteristics of nurses influence nurses' ability to assess pain in the neonate? 
Definition of Terms: As used in this study the following terms are defined as follows:

Pain: an unpleasant sensory and emotional experience associated with actual or potential tissue damage (Bonica, 1979).

Neonate: a human infant during the first four weeks after birth (MillerKeane,1972).

Assessment: evaluating how infants behave and react to pain.

Behavioral assessment: includes measures of facial expression, body movement, behavioral state, and cry.

Physiologic assessment: includes a broad range of measures such as heart rate, respiratory rate, blood pressure, intracranial pressure and palmer sweating (Porter, 1989).

Registered Nurse: A graduate nurse registered and licensed to practice nursing by a State Board of Nurse Examiners or other state authority (MillerKeane,1972).

Inservice Education: A one hour session examining various aspects of neonatal pain. Topics covered are pain theories, effects of pain on the neonate, pain assessment parameters, differentiating pain verses agitation, pain interventions, and the role of the nurse in assessing and intervening when the neonate is experiencing pain.

\section{Significanceof the Study:}

A major goal of all nursing care is the relief of suffering. Nurses in the clinical setting are in an ideal position to assess the pain of infants, influence management, and occasionally prevent painful procedures from occurring. If a nurse has been educated in pain recognition the nurse will be in a better position to give effective nursing care. Comprehensive assessment is the first step to improve pain management. 
Communication to other health professionals should be objective and infant focused. Ongoing evaluation and patient advocacy must become the responsibility of the nurse.

The NICU nurse is expected daily to administer painful procedures to neonates. If we can increase the nurses' awareness of neonatal pain (pain perception and it's effects) through inservice education nurses will be better equipped to be effective patient advocates. Our nursing goal is to alleviate pain and suffering. Focused educational programs can facilitate the attainment of this goal.

Nurses as the patient's advocate should be able to assess the newborns pain after gaining a better concept of neonatal pain through inservice education. The nurse advocate would then be able to communicate these findings to the members of the health care team, and then together be able to implement a treatment plan for relieving pain.

Neonatal pain research has taken off in the last ten years. Further research is needed in many areas. The development of a valid assessment tool, the development of alternative methods of pain relief, and long term follow up studies of the effects of neonatal pain on future development, are just a few needed research areas. Studies to better assess the presence of pain and stress in the NICU infant and to evaluate the effectiveness of pharmacologic treatment are ongoing.

The results of this study could be used as a base for further research looking at nurses documentation in pain assessment skills. Do nurses who have participated in a neonatal pain focused inservice improve in pain assessment documentation more than nurses who have not participated in the inservice? Further research could look at improvement in documentation specifically related to behavioral cues neonates exhibit when in pain. Does improving nurses assessment skills increase administration of pain medication to neonates? Also of interest would be looking at the effects of nurses ability to adequately assess the neonate in pain and patient outcome. This study has 
implications for many research projects which will increase nurses ability to assess and adequately care for the neonate in pain. 


\section{Chapter 2}

\section{Review of Literature}

In this chapter a review of the literature that includes theories of neonatal pain, nurse's assessment and recognition of pain, and infants response to pain will be presented. Since infants cannot verbalize the meaning or intensity of pain, the assessment is subjectively determined by the caregiver and subtle signs may go unnoticed. This validates the importance of educating the NICU nursing staff to increase their recognition in assessing neonatal pain.

\section{Pain Theories: An Overview}

An understanding of pain in the newborn might be facilitated by an examination of theories developed to explain pain. This may be accomplished by considering relevant pain theories that may be applicable to this age group.

\section{Gate Control Theory}

The Gate Control Theory which is the most well known theory of pain proposes that peripheral pain impulses travel to the cortical nervous system via ascending pain pathways. These impulses are then modulated by inhibitory processes of the descending pain pathways by a "gating mechanism" at the level of the spinal cord (Johnson, 1986).

This theory was developed by psychologist Ronald Melzack, biologist Patrick D. Wall, and physiologist K.C.Casey (1965). The gate control theory proposes that: (a) noxious sensory input into the nervous system is decreased at perceptual levels through a gating effect at the spinal cord; (b) a large amount of selective stimulation of cutaneous afferent large diameter fibers (pressoreceptor or mechanoreceptor input triggers these fibers) inhibits the pain perception or closes the gate; (c) the inhibitory 
effect is thought to occur at lamina 11 and 111 of the dorsal gray of the cord by activation of inhibitory cells within the substantial gelatinosa; and (d) if the greatest amount of selective stimulation comes along as input to the small diameter fibers, inhibition of the inhibitory cells of the substantial gelatinosa occurs, thus opening the gate for greater pain perception (Wolf,1980).

Secondary neurons then synapse with other neurons in the spinal cord, called projection neurons. These projection neurons travel to the thalamus and the cortex of the CNS via ascending pain pathways and supraspinal mechanisms. The ascending nociception tracts provide information about the sensory dimension of pain, stimulate the motivational affective aspects of pain, activate descending inhibitory systems, and initiate autonomic and motor responses. The ultimate perception of pain is dependant upon the complex modulation of neuronal impulses in ascending pathways in relation to the activation of descending inhibitory systems (Stevens \& Johnston,1993).

Neuromatrix Theory:

In 1989, Melzack introduced the Neuromatrix Theory. In this theory he proposed that the experience of the body self is genetically determined but modified by sensory experiences. The widespread neural network or neuromatrix impacts a unique pattern. The neurosignature on all inputs so that personal experiences have a quality of affective and cognitive meaning.

\section{Emotional Specificity Theory}

The Emotional Specificity Theory believes that pain is a specific emotional response that exists from birth and there is a particular constellation of facial and/or cry patterns from pain that is unique from other emotional states. This model proposes that there is survival value in the uniqueness of the cry and facial behaviors; that is, a helpless infant in pain will cry in a particular manner or show a particular face 
that will signal to the caretaker that he is in pain and needs assistance. Izard (1990) concluded that discrete emotional expressions exist and can be measured in infants.

\section{Stress Arousal Theory:}

In the Stress Arousal Theory, stress is associated with arousal. In infants, arousal is reflected in varying states on a continuum from quiet sleep to active wakefulness and finally crying. The central concept of this theory is that the infants level of arousal depends on the degree of stress. Lester (1984) has shown that infant pain is reflected in increased sympathetic activity (increases in heart rate and also increased body movements, facial action, and crying). In this model the amount of crying increases, but characteristics of the cry that elicit caregiver attention are a reflection of increased innervation to the vocal tract.

Anand and Hickey (1987) suggest that nociception is a more appropriate word than pain when referring to neonates. Nociception is the detection of a painful stimulus in the peripheral nerve endings and the transmission of information at the site of painful stimulation to the brain. Nociception involves the nervous system, where the pain signals are generated and processed, and the endocrine system, which governs the chemical response to pain signals. Anand and Hickey (1987) have shown evidence that the fetal nervous system is sufficiently mature by 20 weeks to experience nociception.

\section{Nurses Assessment of Pain:}

Newborns must rely on the ability of nurses to identify their pain. Newborns exhibit a variety of behavioral and physiologic responses when they are thought to be experiencing pain, but it is not known whether nurses perceive and interpret these same signs as indicating the possibility of pain in the newborn (Jones, 1986). 
Pigeon (1989) used a questionnaire to examine the perception of neonatal nurses as to the indicators and causes of different intensities of neonatal pain. The method used was nurse observation. Forty three questionnaires were received and analyzed. The NICU nurse observed a neonate under her care and listed behaviors that she perceived to be indicative of pain in the infant. Results indicated babies in pain were more likely to be crying, to have marked changes in facial color, and to have rigid limbs and torso, to have irregular breathing, and to be fighting. Greater pain levels were associated with more extreme changes in facial color, marked tension, and tachycardia. The study shows a high level of agreement among nurses about the behaviors they use to assess pain in neonates but their was a very wide range of procedures that nurses perceive as causing pain, and varied in the behavioral indicators for different levels of pain. The study indicates the need for better nursing education in pain assessment and efforts must be made to develop methods to reduce pain.

Jones (1989), designed a Pain Sensitivity Questionnaire asking nurses to identify physiological and behavioral signs suggesting the possibility of pain in the newborn. One hundred and nine surveys were distributed with a $74 \%$ response. The results showed the three signs most frequently selected as "always" were fussiness, crying, and grimacing. The study suggests the difficulty nurses have in making assessments regarding pain in the newborn. These findings also indicate the need for nursing education in neonatal pain.

Shapiro (1993) examined nurses judgments of pain intensity in fullterm and preterm neonates and examined cues that neonatal nurses use to assess the possible presence of pain. Qualitative and quantitative approaches were used.

The method used was videotapes accompanied by written vignettes, visual analogue scales, and open ended questions about pain cues. Forty five neonatal nurses participated in the study. The results showed higher pain intensity ratings to the 
fullterm group then to the preterm group. This study has implications. Neonatal nurses judgment of pain intensity in newborns are influenced by the vigor and richness of the newborns behavior response. So pain in the preterm infant might go unnoticed because the behavior responses are not as significant as the full term infant.

Franck (1987) conducted a national survey to determine beliefs about neonatal pain and agitation, current methods of assessment, and standards of treatment. Seventy six nurses from seventy six neonatal intensive care units responded to the 15 question survey. The majority of the respondents listed cry and activity as the primary means of assessing pain in infants. Findings showed 60 of $76(\%)$ of respondents believe pain medication is underused, indicating that nurses are not communicating their assessments effectively. The study showed a lack of consistency in attitudes and practices among staff in the NICU with regard to infant pain and reported that current practices regarding both pain assessment and management is inadequate.

Page \& Halvorson (1991) conducted a study to explore nurse's attitudes regarding post operative pain in the preverbal infant, including nurses identification of pain cues, and stategies for pain management. One hundred and eight nurses' were surveyed using three instruments developed for the study. The pain questionnaire, a demographic and attitudinal profile, a sleep directed video, and a video questionnaire were used. Three independent variables yielded significant results. They were critical care versus non critical care nurses, agreement versus disagreement to administer pain medication to infants expected to have pain but not exhibiting pain behavior, and attendance of pain classes. The study found non critical care nurses recognized a greater number of pain behavior cues than did critical care nurses.

Penticoff (1989), collected data from a sample of 20 NICU nurses from three separate NICUS over six years and analyzed how nurses view themselves as advocates for infants in the NICUS. The researcher found that nurse advocacy arises out of the 
continual close exposure of neonatal nurses, to infants responses to treatment. Over the time span the researcher found nurses experiencing significant emotional distress when they believed therapies resulted in infant suffering with out proportional benefit All of the nurses interviewed felt infant suffering triggered a variety of acts of advocacy ranging from changes to decrease infant distress to requests that the medical plan of care be reviewed.

Elander, Hellstrom, \& Qvarnstrom (1993) observed 12 infants for 24 hours post operative following major surgery to examine pain management in infants. Analgesic administration, facial expression, vocalization, sleep awake states, and care routines were monitored. The study, however, was limited based on the considererably small sample size and the pain score used was not based on a validated tool. The researchers indicate that the pain management was not consistent and infant care routines need to be evaluated.

\section{Educative Measures Enhancing Nurses Pain Assessment Skills:}

McNauill (1992) designed a study to identify an effective method of teaching nurses to assess and document pain severity using a numerical rating scale before narcotic administration. Nurses received instruction in one of the following ways: (1) letter, (2) letter and personal contact, (3) letter, personal contact, and a poster, (4) letter, personal contact, and a video. The findings suggest that the first method was not effective in ensuring nurse performance in the use of the pain assessment scale. However, when the number of educational techniques were increased performance improved accordingly. Nurses in the fourth group who saw the video used the pain assessment scale nearly twice as often as nurses in all other groups and more than 12 times as often as nurses in Group 1. 
Camp (1991) conducted and evaluated a study involving a continuing education class designed for onocology nurses regarding pain assessment and the need for documentation of that assessment. The study evaluated the different groups of nurses: (a) a control group who attended the class, (b) an experimental group who attended the class and received a laminated pain assessment tool, and (c) a group who did not participate in the class. Effectiveness was measured by extracting pain documentation from the charts. No significant scores were noted across the three groups.

Hamilton (1992) surveyed 318 nursing staff members at a teaching hospital in Canada to identify their knowledge of pain assessment and management. Overall results indicated that nurses lacked knowledge and understanding of opioid addiction, acute and chronic pain. No statistically significant differences were found in the scores by level of educational preparation or by years of experience. Presentation of the results demonstrated that the instrument is suitable as an educational tool.

McGrath (1990) developed a pediatric tool flow sheet to provide health professionals with a simple means of documenting the child's pain experience. This instrument was pretested and used in a research study to ascertain whether its use would make a difference in the child's post-operative pain experience. Results indicated that nurses who implemented the flow sheet had patients who were in less pain, were assessed more, and received more narcotic analgesic.

Davis (1988) described the change process in nurses practice for more effective control of post operative pain through a staff initiated educational program. The staff trialed and developed a pain assessment tool concurrently with a focused educational program on a short stay orthopedic ward. Control of the post operative pain can be improved by preparation and effective use of pain assessment tools. 


\section{Variables Affecting Pain Assessment:}

\section{Nurses Personal Attributes and Experiences:}

Holms (1987) conducted a study on the relationship between nurses' personal pain experience and their assessment of their patients pain. The sample was comprised of 134 nurses working at three hospitals. The major findings were that assessment of a patient's pain is significantly influenced by the intensity of a nurse's personal pain experience. The nurse who has experienced pain is more sympathetic to the patient.

Bagley (1985) felt it was important for nurses to be aware of their own personal biases. Bagley pointed out that biases such as ethnic background, sex, and age of patient could affect how nurses respond to their patients. Bagley found that the opposite also holds true, meaning that the age, sex, and ethnic background of nurses affect how they practice and make decisions concerning pain. She feels it is nursing's professional responsibility to provide quality care to all patients and disregard personal biases.

Burokas (1986) studied factors that affected nurses' decisions to medicate pediatric patients after surgery. She found that decisions to medicate children after surgery were affected by whether or not the nurse had a child of her own who had experienced a painful episode.

\section{Behavioral and Physiologic Changes in Neonatal Pain:}

Recent publication as well as some classic studies provide documentation that strongly supports the existence of pain perception in infants. The following is a review of behavioral (facial expression, vocalization, crying, posture, and movement) and physiologic changes that have been studied in neonatal pain. 


\section{Behavioral Changes:}

Changes in behavioral states following pain suggest that infants are not merely responding reflexively to pain. Striking individual differences in behavioral states following circumcision indicate that even shortly after birth infants have individual styles of coping with pain. Some infants have increased periods of non-rapid eye movement sleep following circumcision similar to what has been observed in adults following prolonged stress (Porter,1989).

Research on the use of regional anaesthesia during circumcision documents the physiologic distress exhibited in unanesthetized infants, such as increased heart rate, prolonged crying, and decreased blood oxygenation as compares to anesthetized newborns (Williamson, 1983).

McGrath (1989) found that infants in pain were more likely to be crying, to have marked changes in facial color, to have rigid limbs and torso, to have irregular breathing, and to be fighting and moving.

McGraw's (1941) work on developmental response of children to pain is the most extensive investigation available. She perfomed a longitudinal-study of 75 children from birth to one year of age for a total of 2008 observations. She used a pin prick as a stimulus and found some infants only a few hours old may exhibit no overt response. However by 7 to 10 days of age most infants react to cutaneous irritation with diffuse bodily movements accompanied by crying and possibly a local reflex withdrawl of the stimulated extremity. The reaction increased in intensity during the first month. By the age of 6 to 12 months the infant exhibited deliberate rather than reflexive withdrawl of the affected limb. By one year of age, infants touched the pricked area after the stimulus was withdrawn.

McGrath (1987) did subsequent research on the nature and intensity of infants motor responses after noxious stimulation. The findings did not corroborate those of 
McGraw's. McGrath found discrepant data about an infant's characteristic motor behavior in reaction to a noxious stimulus. This may represent only apparent contradictions that occur as a consequence of differences in the experimental design among these research studies. Experiments have not been standardized in relation to the time of testing, the nature of the pain inducing stimulus, and the extent to which observers were trained to recognize individual motor behavior in infants. Interesting to note, these contradictions may provide evidence to show there is no specific motor behaviors in neonates. Individual differences in reaction to pain inducing stimuli may exist at birth.

Another explanation for the discrepancy in findings between McGraw and other researchers may be due to the behavioral state of the infant at the time of pin prick. Behavioral state has been shown to affect a number of infant behaviors, such as heart rate, sucking, and facial expressions (Grunau \& Craig, 1987).

Cry has been studied extensively as a possible indicator of infant pain. In depth analysis of cry during circumcision has demonstrated that acoustic features of cries are directly related to the invasiveness of the procedure. With increase in presumed pain neonatal cries become shorter, more frequently emitted in a longer series, and higher with less distinct harmonics (Porter, Miller, \& Marshall, 1986).

Several studies have classified infant crying according to the type of distress indicated. Cries due to pain, hunger, or fear can be distinguished reliably by the subjective evaluation. The pain cry has specific behavioral characteristics. Other studies of the cry response to painful procedures, revealed neonates were found to be more sensitive to pain than older infants (3-12months), but had similar latency periods between exposure to a painful stimulus, or another response (Anand,1987).

Facial expression has been shown to be a strong indicator of the neonates pain experience. The facial actions described were brow bulge, eye squeeze, open lips, lip 
purse, stretch mouth (horizontal or vertical), taut tongue, chin quiver, and progression from latency to action from the time of stimulation (Clancy \& Anand,1992).

Johnston and Strada (1986) used the Maximally Discriminative Facial Movement Coding System (MAX), to assess acute pain response in infants. Their most significant findings were related to the extreme variability among infants, especially in initial cry and heart rate. In the injection phase the heart rate dropped or remained the same in 12 of the 14 subjects, but increased in 13 infants during the post injection phase. Body movements were either rigid or thrashing. The most consistent behavioral responses were facial responses. Eleven of the 14 subjects demonstrated the perfect facial configuration of pain, the others showed anger and sadness expression.

\section{Physiologic Changes:}

Changes in cardiovascular variables, transcutaneous partial pressure of oxygen, and palmer sweating have been observed in neonates undergoing painful clinical procedures. In preterm and fullterm neonates undergoing circumcision or heel lancing, marked increases in the heart rate and blood pressure occurred during and after the procedure. The magnitude of changes in the heart rate was related to the intensity and duration of the stimulus. The administration of local anaesthesia to full term neonates undergoing circumcision prevented the changes in heart rate and blood pressure (Williamson,1983).

Marchette (1991) conducted a study to determine the effect of noninvasive pain reduction intervention on pain in 121 neonates undergoing unanesthetized circumcision. Results indicated that interventions tested did not greatly reduce the neonates circumcision pain as assessed by the variables. The major implications from this study is that stronger pain interventions are warranted for circumcision. 
Owens \& Todd (1984) reported heart rate and elevations in infants in response to heel sticks during routine blood sampling procedures. Johnson (1990) reported that infants in acute pain evoked by injections showed a brief increase in heart rate to a tachycardia level. As infants return to a resting body position, their heart rates remain elevated.

Palmer sweating has also been validated as a physiologic measure of the emotional state in full term babies and has been closely related to their stage of arousal and crying activity. Substantial changes in palmer sweating were observed in neonates undergoing heel stick for blood sampling, and subsequently a mechanical method of heel lancing proved to be less painful than manual methods on the basis of the amount of palmer sweating (Anand \& Hickey,1987).

The research presented clearly indicates that neonates are capable of feeling pain. The need to reduce pain so that infants can grow and develop without using their energies for coping with pain is essential. There is no question that neonates have pain, and by increasing the nurse's assessment skills, they will be better equipped to adequately assess and provide subsequent treatment.

\section{Application of Nursing Theories:}

This study was conceptualized by synthesizing the theories of Neuman, Roy, and Leininger. The concept of the human as a bio-psychosocial being on a continuum of health-illness is the basic premise of Roy's Adaption Model. Because of various stimuli that surround the person, some kind of adaptation is constantly required. Roy identified four modes of adaptation: physiological, self concept, role function, and interdependence.

Roy's model can be used effectively when assessing and treating neonates in pain. The nurse in this perspective must acquire information on all four adaptation 
modes. The stressor pain is identifiable. Once the neonate's behavior in each of the four modes is assessed, potential pain stimuli can be identified, and the adaptive problems defined. Established goals are then set using pharmacological and nonpharmacological interventions for pain relief. The nurse subsequently evaluates the neonate's response and assists the neonate through the adaptive state.

Looking at Bettty Neuman's conceptual framework, the human system is constantly influenced by internal and external stimuli as he/she moves laterally on the wellness/illness continuum. The system is viewed on five variables: psychological, physiological, sociocultural, developmental, and spiritual. Three levels of intervention exist. Primary prevention attempts to reduce the reaction (trying to reduce the amount of painful procedures). Secondary prevention is selected when a reaction to a stressor has already happened (pharmacological/non-pharmacological interventions). Neuman assumes stressors such as pain stimuli are derived from the environment as noxious stimuli having the potential to disturb equilibrium.

When working with the neonate and the family, nurses can use Leininger's theory of Cultural Care. Leininger believes that caring behavior and practice uniquely distinguishes nursing from the contributions of other disciplines. Care is the essence of nursing and the dominant, distinct, and unifying feature of nursing.

Nurses can try to meet the needs of the family by giving culturally competant care to the infant and the family. Leininger states, "We are entering a new phase of health emphasis as we examine the impact of cultural factors upon human caring, health and illness behaviors". 


\section{Hypothesis:}

This study seeks to determine whether an educational inservice program makes a difference in nurse's knowledge of neonatal pain assessment. Three hypotheses were formulated based on the literature review and conceptual framework:

1. Nurses knowledge about assessment of neonatal pain will improve following participation in a pain focused inservice program.

2. Nurses who have higher levels of nursing education have more knowledge in neonatal pain assessment than nurses who have lower levels of nursing education.

3. Nurses who have more neonatal nursing experience show more knowledge of neonatal pain assessment than nurses with less neonatal experience.

\section{Research Question:}

To what extent do personal characteristics (age, gender, marital status, number of children, ethnicity) influence nurses' abilities to assess pain in the neonate.

\section{Operational Definitions:}

Assessment: evaluating how neonates behave in response to pain.

Neonate: a newborn infant $0-30$ days of age.

Pain: an unpleasant sensory and emotional experience associated with actual or potential tissue damage (Bonica,1979) indicated by any of the following: (1) increase or decrease in heart rate, (2) increase or decrease in blood pressure, (3) increase or decrease or a change in respirations, (4) dilating pupils, (5) flushing or pallor, (6) restlessness or fussiness, (7) grimacing, (8) wrinkling of forehead, (9) widening of 
eyes, (10) tightening shut of eyes, (11) crying, (12) clenching of fists, (13) flexing or extending of extremities, (14) rigidity (15) kicking (Franck, 1986, Jones, 1989, Williamson, 1983). 


\section{Chapter 3}

\section{Methodology}

\section{Design:}

A quasi-experimental pretest and posttest research design was selected for this study. The study surveyed nurse's assessment of pain using a General Information and Pain Sensitivity Questionnaire developed by Jones (1989).

After the initial survey, the questionnaire was collected and the nurses were inserviced on neonatal pain assessment. A one hour inservice education program was used which examined pain theories. The effects of pain on the neonate, pain assessment parameters, differentiating pain versus agitation, and pain interventions were considered. The role of the nurse in assessing and intervening when the neonate is experiencing pain was discussed incorporating research data that examines the way nurses interpret pain.

One week after the intervention the nurses' were asked to complete the same questionnaire again. Data analysis involved comparision of pre- and post-intervention findings. Descriptive and inferential statistics were used where applicable.

\section{Sample:}

A convenience sample was selected for this study according to the following criteria:

1. Are registered nurses employed in the neonatal and special care nursery units at a Children's Hospital in the Miami area.

2. Are able to speak, read, and understand English.

3. Agree to participate in this study through informed consent.

The sample was derived from nurses working in NICU and special care nurseries. This sample reflected a multicultural/ethnic mix and included female nurses only. 


\section{Instrument:}

The instrument chosen for use in this study is a General Information Questionnaire and Pain Sensitivity Questionnaire developed by Jones (1989). The general information questionnaire was used to obtain demographic data and identify variables that could influence a nurses perception of neonatal pain. This tool accounted for variables that might be related to the number of signs a nurse could interpret as pain in the newborns. This tool was developed from literature on pain in infants and children.

The physical signs are grouped according to categories or domains: physiological, attention/anxiety, facial, vocal and body movement. Each sign is rated on a scale of $0-4$ with the numbers having the following designation: $0=$ never, $1=$ rarely, $2=$ sometimes, $3=$ usually, $4=$ always.

\section{Validity:}

Content validity of Jones' tool has been established with nursing experts who had developed a pain assessment tool for children. These nursing experts reviewed the questionnaire and felt it represented a valid tool to assess pain in the newborn. Revisions of the format of the questionnaire were made based on the recommendations of the experts.

\section{Reliability:}

Jones (1989) used a test-retest method to establish reliability of the pain sensitivity questionnaire in the pilot study. The questionnaire was administered to nine registered nurses who worked with newborns and functioned in administrative or educational roles in the same area as the sample was selected. A week later the same 
group of nurses were given an alternate form which required listing those behavioral/ physiological signs that they always/never look for when assessing pain in the newborn. Sixty-five percent agreement of responses was obtained for the instrument reliability in the pilot study. In the present study the tool was tested for internal consistency. The statistical test revealed a positive correlation in all given testing periods, which lends further support for the reliability of this tool. Beyer and Knapp (1986), agree that test-retest with a short time span between tests is probably the best current method of establishing reliability for pain assessment.

\section{Data Collection:}

Approval to conduct the study was obtained from the Director of Neonatology, and the Research Committee from the participating institution prior to data collection. Subjects were recruited once the research protocol was approved by the respective institutions, including Florida International University.

The investigator presented an overview of the study to the staff nurses prior to participation. Clarification of purpose, data collection, procedure and request for participation was discussed at the meeting. Potential subjects who chose to participate in the study were asked to respond to a set of questions. Also, they were asked not to discusss their responses with each other, permitting confidentiality of information and preventing potential data contamination. The one hour inservice program was given to the staff after the initial survey. One week later the staff was surveyed again using the same tool.

\section{Data Analysis.}

The data were organized into two parts. Part 1, the Demographic Section, is composed of 13 questions, and Part 2, the Pain Sensitivity Section, is made up of 34 
questions. A code book was designed to prepare the data for entry and analysis. The data were analyzed using the Statistical Package for the Social Sciences (SPSS).

Questions 1-13 on the demographic section yielded data defined as categorical (e.g. sex, age, race, religious preference, nursing education, number of years practicing as a registered nurse, number of years caring for hospitalized newborns, marital status, number of children, and ages of children). The data were analyzed using descriptive methods to characterize the sample.

The pain sensitivity data (Part 2) were analyzed using the t-test for paired samples, correlation coefficients, t-test for independent samples, Levene's test for equality of variances, and one way ANOVA. To determine if the intervention made a difference, the t-test for paired samples was used testing the significance of the difference between the pre-test and post-test means. The results of this statistical test provided the basis for accepting or rejecting the researcher's hypotheses. 


\section{Chapter 4}

\section{Presentation of Findings}

This chapter presents the findings of this study. Tables depicting the findings with regard to demographics, the research question, the hypothesis and incidental findings are included.

\section{Characteristics of the Sample}

A total of 60 nurses participated in the study. Of these, 49 were included in the analysis. Four of the participants who participated in the pre- and post-survey and the inservice were not registered nurses, and hence they were excluded from data analysis. Seven nurses who attended the pretest and the inservice did not complete the post test, and they, too, were excluded from the study sample. The remaining 49 questionnaires were subsequently coded and submitted for statistical analysis. The frequency distributions of the subjects by demographic factors are presented in the following tables.

The sample met the selection criteria and was comprised of female nurses ranging in age from 23 to 58 years with a mean age of 37.19 years. As displayed in Table 1 , white respondents comprised the majority $(54.2 \%)$. There were as many Black respondents as well as Hispanic which altogether comprised $20.4 \%$ of the sample group. 
Concerning religion the majority of the respondents were Catholic (42.9\%), followed by Protestant (33.5\%). Protestant respondents reflected different denominations: Baptist, Christian, Lutheran, Episcopal, Church of God,and Seventh Day Adventist. Six percent of the respondents reported being Jewish. Those with missing data comprised $17.5 \%$ of the sample.

Table 1: Frequency Distribution of the Sample by Ethnicity and Religion

Demographic Variable Frequency Percent

\section{ETHNICITY}

White

Black

Hispanic

American indian

Other
29

5

5

1

9

49

\section{RELIGION}

Catholic

Protestant

Jewish

Missing
21

17

3

8

49
$54 \%$

$10.2 \%$

$10.2 \%$

$2 \%$

$18.4 \%$

$100 \%$ 
The majority of the subjects were prepared at the baccalaureate nursing level (Table 2). There were about as many graduates of associate nursing programs as diploma programs. Only one subject was prepared at the Master's Level. The sample was predominately married. Nearly $25 \%$ were single and less than $15 \%$ were divorced.

Table 2: Frequency Distribution of the Sample by Education and Marital Status.

Demographic Variable Frequency Percent

\section{EDUCATIONAL BACKGROUND}
A.D.
12
$24.5 \%$
Diploma
11
$22.4 \%$
B.S.N.
24
$49 \%$
M.S.N.
1
$2 \%$

MARITAL STATUS

Married

30

$61.2 \%$

Single

12

$24.5 \%$

Divorced

$14.3 \%$ 
As depicted in Table 3, the majority of the sample had children $(59.2 \%)$, commonly two in number. Of these nurses, $55 \%$ had children over age ten, and $45 \%$ had children under age ten.

Table 3: Frequency Distribution of the Sample by Number and Age of Children

Demographic Variable Frequency Percent

NUMBER OF CHILDREN

none

One

Two

Three

Four

AGE

children $<10$ years

children $>10$ years
49

29

20

9

13

6

1

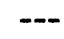

14

15

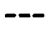

$40.8 \%$

$18.4 \%$

$26.5 \%$

$12.2 \%$

$2 \%$

$100 \%$

$45 \%$

$55 \%$

$100 \%$

The majority of the sample (75.5) are working presently in the NICU. As many as $16.3 \%$ worked in the NICU and other areas of the hospital. Only $8.2 \%$ work in the special nursery. 
Table 4; Frequency Distribution of the Sample by Setting.

Work Setting

Frequency

Percent

NICU

37

$75.5 \%$

Special Care Nursery

4

$8.2 \%$

Others (with NICU

8

$16.3 \%$

experience)

It is interesting to note that the nursing experience of the nurses in this study varied from one month to 30 years. The mean number of years in nursing was 12.22 years. The number of years of experience relating to the care of hospitalized newborns, age $0-28$ days, ranged from one month to 30 years. The mean number of years of such experience was 8.22 years. 
As illustrated in Table 5 the majority of the sample (75\%) had not taken infant specific pain courses in their nursing practice. Barely $31 \%$ indicated having had some type of child specific pain course. The majority of these nurses $(77 \%)$ reported not having taken any pain courses in their nursing program.

Table 5: Proportion of Sample who had Taken Courses in Pain in their Nursing Practice

\begin{tabular}{lcc}
\hline Infant pain course & Frequency & Percent \\
yes & 12 & $24.5 \%$ \\
no & 37 & $75.5 \%$ \\
& & \\
Child pain course & Frequency & Percent \\
yes & 15 & $30.6 \%$ \\
no & 34 & $69.4 \%$ \\
\hline
\end{tabular}

\section{Findings Related to the Hypothesis:}

Hypothesis 1: Nurses' knowledge about assessment of neonatal pain will improve following participation in a pain focused inservice program.

To test this hypothesis, a paired t-test was done on the pre- and post-test scores to see if the educational inservice made a difference in nurses knowledge of neonatal pain assessment. Statistical analyses were done on overall scores as well as 
scores by specific domains of physiological, attention/anxiety, facial, vocal, and body movements. The findings are illustrated in Table 6 .

Table 6: Summary of Paired T Test Results on Pre and Post-test Pain Assessment Scores by Specific Domains and Overall Scores $(\mathrm{N}=49)$.

\begin{tabular}{|c|c|c|c|c|c|c|c|}
\hline \multirow[b]{2}{*}{ Pain Assessment } & \multirow[b]{2}{*}{ mean } & \multirow{2}{*}{$\begin{array}{l}\text { pretest } \\
\text { sd }\end{array}$} & \multicolumn{2}{|c|}{ posttest } & \multirow[b]{2}{*}{ tvalue } & \multirow[b]{2}{*}{ df } & \multirow[b]{2}{*}{2 tailed significance } \\
\hline & & & mean & sd & & & \\
\hline $\begin{array}{l}\text { Specific Domains } \\
\text { attention/ }\end{array}$ & & & & & & & \\
\hline anxiety & 2.84 & .895 & 2.87 & .663 & -.37 & 48 & .713 \\
\hline body movement & 2.47 & .631 & 2.87 & .631 & -3.11 & 48 & $.003 *$ \\
\hline facial & 2.7653 & .662 & 3.0663 & .690 & -2.50 & 48 & .16 \\
\hline physiological & 2.3701 & .634 & 2.6207 & .631 & -2.50 & 48 & $.007 *$ \\
\hline vocal & 2.945 & .789 & 2.7848 & .593 & -.33 & 48 & .745 \\
\hline rall & 2.5706 & .509 & 2.7848 & .593 & 2.89 & 48 & .006 \\
\hline
\end{tabular}

* significance; critical $\mathrm{p}<.05$

The t-test for paired samples for Hypothesis 1 showed an increase in means in two specific domains and in total pain assessment test scores. Specifically, differences between pre-test and post-test scores were found in nurses assessment knowledge relating to body movement $(p=.003)$ and physiological $(p=.007)$ domains.

Overall, there was a significant increase in post test scores, a gain of .21 points over the groups pre-test scores. This finding, significant at $p=.006$, lends support for Hypothesis 1. 
Hypothesis 2: Nurses with higher levels of nursing education have more knowledge in neonatal pain assessment than nurses who have lower levels of nursing education.

The Spearman correlation coefficient test was used to test this hypothesis. The educational levels were ranked from 1 to 4 (1=A.D., $2=$ Diploma, $3=\mathrm{BSN}$, and $4=$ MSN). Since these are ordinal data, the Spearman correlation coefficient test was preferable over the Pearson correlation coefficient for analysis of this data.

Table7: Relationship Between Nurse's Educational Level and Nurse's Knowledge of Neonatal Pain Assessment $\mathrm{N}=48$

\begin{tabular}{lccc} 
& Total pretest & Total posttest & Difference \\
\cline { 2 - 3 } & & & \\
Spearman $\mathrm{r}$ & .2100 & .1718 & .0714 \\
2 tailed significance & .152 & .243 & .630 \\
& & & \\
\hline
\end{tabular}

The statistical analysis indicates no significant correlation between nurse's educational level and their pain assessment scores before and after participation in the pain focused educational inservice program. Education did not make a difference in nurse's knowledge of neonatal pain assessment. This finding failed to support Hypothesis 2. 
Hypothesis 3: Nurses who have more neonatal nursing experience show more knowledge of neonatal pain than nurses with less neonatal nursing experience.

The Pearson correlation coefficient test was used in data analysis and the results indicate no significant relationship between nursing experience and knowledge of neonatal pain. This study failed to demonstrate adequate evidence to support Hypothesis 3.

Table 8: Relationship Between Total Years Taking Care of Hospitalized Infants, and Years in Nursing with Knowledge of Neonatal Pain Assessment $(\mathbf{N}=48$. $)$

Total Xears taking care

of hospitalized infants

Pearson $\mathrm{r}-1046$

$-.0633$

2 tailed significance

Total years of nursing

Pearson $\mathrm{r}$

2 tailed significance 


\section{Findings Related to the Research Question}

To what extent do personal characteristics (age, marital status, number of children, ethnicity) influence nurses ability to assess pain in the newborn?

An ANOVA was used to analyze the following variables (age range of children, marital status, and highest level of education). For such variability as race, marital status, and number of children a t-test for independent samples was used.

The ANOVA and the t-test did not yield any significant findings between the variables and the nurse's ability to assess neonatal pain as measured by the Pain Assessment Questionnaire. 


\section{Chapter 5}

\section{Discussion, Conclusions, Implications, and Recommendations}

The purpose of this chapter is to discuss the findings and conclusions that can be drawn from this study. The limitations and recommendations of this study are also addressed.

\section{Discussion of Findings}

The assessment of neonatal pain has been shown to be a difficult task due to misconceptions held by nurses. The purpose of this study was to increase nurses knowledge of neonatal pain through an inservice education program. The pain assessment questionnaire developed by Jones (1986) was utilized to evaluate the effectiveness of the inservice program.

The findings depict strong support $(p=.006)$ for Hypothesis 1 that " Nurses' knowledge about assessment of neonatal pain will improve following participation in a pain focused inservice program". The educational inservice made a significant difference in nurse's knowledge of neonatal pain assessment.

In this study formal instruction in pain assessment included several important dimensions: (1) obstacles to the assessment of neonatal pain for the neonate and the bedside nurse, (2) effects of pain on the neonate, (3) circumstances under which the neonate will experience pain, (4) physiological assessment of pain in the neonate, (5) behavioral assessment of pain in the neonate, and (6) differentiating pain versus agitation.

Neonatal nurses must be provided with continuing education that focuses on the above dimensions. Assessment of pain is particularly important to nurses, yet 
nurses may experience uncertainty and ambiquity in assessing the behavioral and physical signs manisfested by infants. Pain assessment is further complicated by nurses' inability to set order of priorities regarding pain management. Often, nurses or physicians are not held accoutable for infant's pain and this aspect of care may be overlooked by more concrete medical issues. McNaull (1992) approached pain management education using a variety of methods. Page (1991) also found that pain classes appeared to enhance nurses' assessment skills. Knowledge of infant growth and development must be addressed in continuing education programs to continually reinforce nurses knowledge of developmental changes in infants perceptions and experiences of pain. Given this, nurses are likely to better assess and manage pain as observed in infants.

The findings concerning Hypotheses 2 and 3 indicate that neither educational level or nursing experience can make a difference in nurses' knowledge of pain assessment. These results compare to the study of Hamilton (1992), who surveyed 318 Canadian nurses. The findingd showed no correlation between nurses knowledge of pain assessment and their level of educational preparation or years of nursing experience. Burokas(1985), on the other hand found that regardless of their educational background or experience, nurses tend to underestimate neonates pain. The nurses relied on their own inferences about the pain rather than using assessment skills.

Shapiro (1993) also found no correlation between pain assessment scores and nurses' years of experience, levels of education, or parental status. One might surmise that the longer a nurse worked and the greater the nurses' level of clinical experience, the more adept he or she would be at recognizing pain. Perhaps the process of arriving at the pain intensity scores differed among the nurses of different levels of 
experience, but it made no difference with the findings. The responses among the nurses may be a reflection of the difficulty they have in recognizing pain in newborns.

Although personal characteristics, experience, and educational levels were not a deciding factor in nurse's knowledge of neonatal pain assessment, the inservice made an impact on all nurses who participated. The majority of the respondents reported never having an educational inservice on infant and pediatric pain and $77 \%$ of the respondents reported never having a pain course in their nursing curriculum. This is an interesting finding, particulary because this study took place in a Children's

Hospital, and the majority of the respondents were BSN graduates (49\%). Nursing education programs no doubt place minimal emphasis on assessment and management of infant pain. If pain is addressed, the focus is usually on the adult model of acute pain, with little attention paid to infants and children.

\section{Summary:}

Nurses at the bedside are faced with the daily dilemma of managing infants pain. The nurse must become the patient advocate and make every effort to recognize physiologic and behavioral indicators of pain in the neonate.

Effective advocacy requires the ability to accurately assess the infants pain. Interventions to meet the neonate's and family's needs must be advocated by all members of the health care team to be effective.

The nursing staff in the NICU is the primary care giver and source of information to the parents. Nurses need to be educated in neonatal pain assessment so they can give accurate information and provide effective nursing care. The literature strongly supports the belief that infants feel pain. This study attempted to show that an educational inservice program on neonatal pain would increase nurses' knowledge 


\section{Limitations}

Caution must be observed in interpreting or applying the findings of this study. A major limitation relates to methodology. The sample involved nurses employed at one Children's Hospital. This eliminated potentially valuable information from nurses employed in other neonatal intensive care units in the area.

Also, subject selection was made by convenience sampling. There was no control group, and comparisons could not be made between nurses who have participated in the inservice educational program and those nurses who had not.

Another limitation relates to the parametric properties of the assessment questionnaire. Jone's (1986) tool has not been adequately tested for it's reliability and validity as a measure of nurses' knowledge to assess neonatal pain.

\section{Recommendations for Future Studies}

1. Increase the sample size and randomize the subjects to achieve generalizibility of the findings.

2. Improve the pain assessment tool to enhance it's parametric properties.

3. Replicate the study in other settings and with different population segments to allow comparison and improve the generalizibility of the findings. 


\section{References}

Als,H (1986). Toward a Synactive Theory Of Development. Infant Mental Health Journal, 3, (4), 229-243.

Anand, K. \& Hickey, P.R. (1987). Pain and its effects in the Human Neonate and Fetus. The New England Journal of Medicine, 21, (317), 1321-1329.

Bonica, J. (1979). The need of a Taxonomy. Pain, $\underline{6}$, (3), 247-252.

Bozzette, M. (1993). Observation of Pain Behavior in the NICU: An exploratory study. Journal of Perinata; and Neonatal Nursing, 7, (1), 76-87.

Broome,M. \& Tanzillo,H. (1990). Differentiating between pain and agitation in premature infants. Journal of Perinatal and Neonatal Nursing, 4, (1), 53-62.

Burokas,L. (1986). Factors affecting nurse's decisions to medicate pediatric patients after surgery. Heart and Lung, 14, 373-379.

Clancy,G. Anand,K. (1992). Neonatal Pain Management. Critical Care Nursing Clinics of North America, 4, (3), 527-535.

Cunningham, N. (1990). Ethical perspectives on the perception and treatment of neonatal pain. Journal of Perinatal and Neonatal Nursing, 4, (1), 75-83.

Dale, J.C. (1986). A Multidimensional study of infants response to painful stimuli. Pediatric Nursing, 12,-(1), 27-31.

Elander, G., Hellstrom, G., Qvarnstrom, B. (1993). Care of Infants after Major Surgery: Observation of Behavior and Analgesic Administration. Pediatric Nursing, 19. (3), 221-227.

Franck, L. (1992). The influence of sociopolitical, scientific, and technologic forces on the study and treatment of neonatal pain. Advances in Nursing Science, 15, (1), 11-20.

Franck, L.(1989). Pain in the Nonverbal Patient: Advocating for the Critically Ill Neonate. Pediatric Nursing, $15,(1), 65-68$.

Franck, L. (1989). A National Survey of the Assessment and Treatment of pain and agitation in the Neonatal Intensive Care Unit. Journal of Obstetric, Gynecologic, and Neonatal Nursing, 16, (19), 387-393. 
Grunau, R., Craig, K. (1987). Pain Expression in neonates: facial action and cry. Pain, 28, $395-410$.

Holm, K., Cohen,F., Dudas,S., Medama,P. (1989). Effect of Personal Pain Experience on Pain Assessment. Image, 21, (2), 72-76.

Izard,C.E. (1990). The young infants ability to produce discrete emotional expressions. Developmental Psychology, 16, (1), 132-140.

Johnston, C., Strada, M. (1986). Acute pain response in infants: A multidimensional description. Pain, 24, 373-382.

Jones, M. (1989). Identifying Signs that Nurses Interpret as Indicating Pain in Newborns. Pediatric Nursing, 15, (1), 76-81.

Lester, B. (1984). Infants Born at Risk. New York: Spectrum.

McGrath, P. (1990). Pain in Children. New York: Guilford Press.

McGrath,P. (1987). An Assessment of Childrens Pain: A

Review of Behavioral, Physiological, and Direct Scaling Technique Pain, 31, 147-186.

McGraw,M. (1941). Neural Maturation as exemplified in the changing reactions of the infant to pin prick. Child Development, 12, 31-41.

McNaull,F. (1992). A Comparison of Educational Methods to Enhance Nursing Performance in Pain Assessment. The Journal of Continuing Education in Nursing, 23 , (8), 267-272.

Owens, M., Todt, T. (1984). Pain in Infancy: Neonatal

reaction to a Heel Lance. Pain, 20,77-86

Page, G. (1991). Pediatric Nurses: The Assessment and Control of Pain in Preverbal Infants. Journal of Pediatric Nursing, 24, (8), 987-995.

Penticoff, J. (1989). Infant Suffering and Nurse Advocacy in Neonatal Intensive Care. Nursing Clinics of North America, (8), 987-995.

Pigeon, H., McGrath, P. (1989). Nurses Perceptions of Pain in the Neonatal Intensive Care Unit. Journal of Pain and Symptom Management, 4, (4), 179-183.

Polit, D., Hunglar,B. (1991). Nursing Research: Principles and Methods. Philadelphia: J.B. Lippincott Company. 
Porter, F. (1989). Pain in the Newborn. Clinics in Perinatology, 16, (2), 549-561.

Shapiro,C. (1989). Pain in the Neonate: Assessment and Intervention. Neonatal Network, 8 , (1), 7-19.

Shapiro,C. (1993). Nurses Judgements of Pain in Term and Preterm Newborns. Journal of Obstretic, Gynecologic, and Neonatal Nursing, 22, (1), 41-47.

Williamson, P. (1983). Physiologic stress reduction by a local anaesthetic during circumcision. Pediatrics, 71, (1), 36-40. 
Appendix 1

\section{INFORMED CONSENT FOR NURSES ASSESSMENT OF NEONATAL PAIN}

I freely and voluntarily consent to be a participant in a research study entitled "Nurses Assessment of Neonatal Pain" to be conducted at Miami Children's Hospital with Carol Beloff, graduate student, at the Principal Investigator. I have been told that my participation in this study will last about 60 minutes. I understand that the purpose of this study is to find out whether a focused inservice pain education program will improve neonatal nurses' ability to assess pain in neonates.

The study will be as follows: I will be asked to complete the attached questionnaire. The first part of the questionnaire will ask questions about my background. The seond part will ask what behavioral and physiological signs and symptoms I look for when assessing pain in the neonate. After completion of the questionnaire, I will attend a one hour inservice program on neonatal pain. One week later, I will be asked to complete the same questionnaire again.

I understand that there are no known risks involved in this study. The benefit that I might get is the possibility of improving my assessment of neonatal pain. I have been told that my responses will be kept strictly confidential and will be identified only by code numbers. My individual response will not be revealed to anyone without my expressed permission.

I understand that I may withdraw my consent and discontinue participation in this research study at any time with no negative consequences. I have been given the right to ask questions concerning the procedure, and my questions have been answered to my satisfaction.

I understand if I desire further information about this study, I should contact Carol Beloff, Principal Investigator at 433-5416, or Dr. Luz Porter, Major Professor, 
at FIU Graduate Nursing program at 940-5971. I have been offered a copy of this signed informed consent.

I have read and understand the above and voluntarily consent to participate.

Participant's Signature

Date

A summary of the findings of this study will be sent to me upon request.

I do/do not want a summary of the findings. Please circle.

Researcher's Signature

Date 
Appendix 2

\section{NEONATAL PAIN ASSESSMENT}

Presenter: Carol Beloff, R.N.

Content Description:

This presentation will examine various aspects of neonatal pain. This includes pain theories, effects of pain on the neonate, pain assessment parameters, differentiating between pain versus agitation, pain interventions, the role of the nurse in assessing and intervening when the neonate is experiencing pain, and research data that examines the way nurses interpret pain in neonatal patients.

Behavioral Objectives:

1. Describe the effects of pain in the neonate.

2. Describe physiological and behavioral assessment of pain in the neonate.

3. Describe pharmacological and nonpharmacological interventions.

4. Discuss the role of the nurse in neonatal pain assessment. 
Appendix 3

\section{GENERAL INFORMATION QUESTIONNAIRE}

Please complete the following questions by filling in the blank or by checking the blank which applies to you:

1. Sex: a

Male

b. Female

2. Age:

3. Race
a. Black
c.
American Indian
b. White
d. Hispanic

e.

4. Religious Preference

5. Nursing Education Completed:
a.
A.D.
c.
Diploma
e.
B.S.N.
b.
M.S.N.
d.
Doctorate
f. Other (explain)

6. Number of years practicing as a registered nurse:
a.
Years
b.
Months

7. Number of years caring for hospitalized newborns, who are 0-28 days of age:
a. Years
b. Months

8. Marital Status:

Married a

Single $b$

Divorced $\mathrm{c}$

9. Number of your own children

10. Ages of your own children 
11. Have any of your children had to be hospitalized?
a. Yes
b. No

If yes, please describe reason for admission of child (children), length of stay, and age (ages) of child (children) involved.

12. Did you have any course in your academic nursing program dealing with assessment of pain?
a.
Yes
b. No

If yes, please describe content of education and length of course concerning pain.

13. Have you attended any programs on the topic of pain? (Please place a check mark beside each program that you have attended.

Adult pain ( 15 years - 100 years)

Pain in Children ( 1 year - 14 years)

Infant Pain (1 month - 12 months)

Pain in Newborns (0 - 28 days)

14. Area of Work

NICU

PICU

Special Care Nursery

Other 
Appendix 4

\section{PAIN ASSESSMENT QUESTIONNAIRE}

What behavioral and physiological signs/symptoms do you look for an interpret as indicating the possibility of newborn pain?

DIRECTIONS: Imagine that you are working with a newborn that has unknown pathology. Please go through the list of signs/symptoms and place a check on the line above the word that best describes how frequently you look for that particular sign/ symptom when assessing for the possibility that the newborn is experiencing pain.

\section{PHYSIOLOGICAL}

1. Increasing heart rate

Never

(0)

\section{Rarely}

(1)

(2)
Usually

(3)
Always

(4)

2. Short, shallow respirations

\section{Never}

(0)

$$
\text { Rarely }
$$

(1)

\section{Sometimes}

(2)
Usually

(3)
Always

(4)

3. Decreasing respiration

Never

(0)

\section{Rarely}

(1)

\section{Sometimes}

(2)
Usually

(3)
Always

(4)

4. Gasping 


\begin{tabular}{|c|c|c|c|c|}
\hline $\begin{array}{c}\text { Never } \\
(0)\end{array}$ & $\begin{array}{c}\text { Rarely } \\
\text { (1) }\end{array}$ & $\begin{array}{l}\text { Sometimes } \\
\text { (2) }\end{array}$ & $\begin{array}{c}\text { Usually } \\
\text { (3) }\end{array}$ & $\begin{array}{c}\text { Always } \\
\text { (4) }\end{array}$ \\
\hline
\end{tabular}

5. Increasing blood pressure

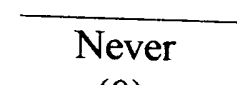

(0)

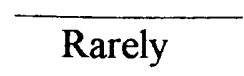

(1)

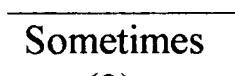

(2)

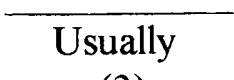

(3)
Always

(4)

6. Dilating pupils

Never

(0)

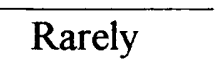

(1)

7. Decreasing heart rate
(0)
Never

(1)

Sometimes

(2)

(2)

Usually

(3)

Always

(4)
Usually

(3)
Always

(4)

8. Pallor

$\left.\begin{array}{l}\text { Never } \\ (0)\end{array}\right)$ Flushing

Never

(0)

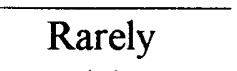

(1)

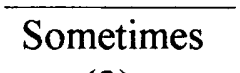

(2) 
12. Increasing respiration

\begin{tabular}{|c|c|c|c|c|}
\hline $\begin{array}{c}\text { Never } \\
(0)\end{array}$ & $\begin{array}{c}\text { Rarely } \\
\text { (1) }\end{array}$ & $\begin{array}{l}\text { Sometimes } \\
\text { (2) }\end{array}$ & $\begin{array}{c}\text { Usually } \\
(3)\end{array}$ & $\begin{array}{c}\text { Always } \\
\text { (4) }\end{array}$ \\
\hline
\end{tabular}

\section{ATTENTION/ANXIETY}

13. Sleeplessness

\begin{tabular}{|c|c|c|c|c|}
\hline $\begin{array}{c}\text { Never } \\
(0)\end{array}$ & $\begin{array}{c}\text { Rarely } \\
\text { (1) }\end{array}$ & $\begin{array}{c}\text { Sometimes } \\
\text { (2) }\end{array}$ & $\begin{array}{c}\text { Usually } \\
\text { (3) }\end{array}$ & $\begin{array}{c}\text { Always } \\
\text { (4) }\end{array}$ \\
\hline
\end{tabular}

14. Restlessness

Never

(0)

(1)

Sometimes

(2)

Usually

(3)

Always

(4)

15. Fussiness

Never

(0)

16. Alertness

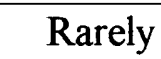

(1)

(0)
(1)

Rarely

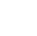


19. Wrinkling of forehead

\begin{tabular}{|c|c|c|c|c|}
\hline $\begin{array}{l}\text { Never } \\
(0)\end{array}$ & $\begin{array}{c}\text { Rarely } \\
\text { (1) }\end{array}$ & $\begin{array}{l}\text { Sometimes } \\
\text { (2) }\end{array}$ & $\begin{array}{c}\text { Usually } \\
\text { (3) }\end{array}$ & $\begin{array}{c}\text { Always } \\
\text { (4) }\end{array}$ \\
\hline
\end{tabular}

20. Widening of eyes
Never
(0)
(1)
21. Shutting eyes tightly

Sometimes

(2)

$\begin{gathered}\text { Never } \\ (0)\end{gathered}$
VOCAL
22. Sobbing

Rarely

(1)
Sometimes

(2)
Usually

(3)
Usually

(3)
Always

(4)

(4) 
26. Twisting

\begin{tabular}{|c|c|c|c|c|}
\hline $\begin{array}{l}\text { Never } \\
(0)\end{array}$ & $\begin{array}{c}\text { Rarely } \\
\text { (1) }\end{array}$ & $\begin{array}{c}\text { Sometimes } \\
\text { (2) }\end{array}$ & $\begin{array}{c}\text { Usually } \\
\text { (3) }\end{array}$ & $\begin{array}{c}\text { Always } \\
\text { (4) }\end{array}$ \\
\hline
\end{tabular}

27. Clenching of fist

Never

(0)

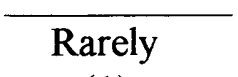

(1)

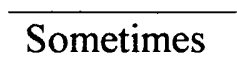

(2)

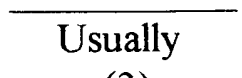

(3)
Always

(4)

28. Extending arms

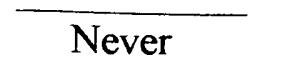

(0)

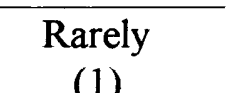

(1)
Sometimes

(2)
Usually

(3)
Always

(4)

29. Extending legs

Never

(0)

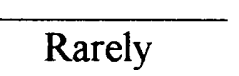

(1)
Sometimes

(2)
Usually

(3)
Always

(4)

30. Flexing of arms

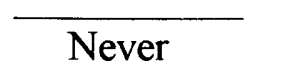

(0)

Rare

(1)
Sometimes

(2)

\section{Usually}

(3)
Always

(4)

31. Flexing of legs

Never
$(0)$
32. $\quad$ Rigidity

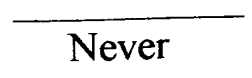

(0)

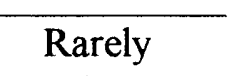

(1)
Sometimes

(2)
Usually

(3)
Always

(4)

Never

(0)

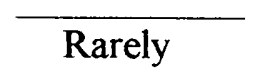

(1)

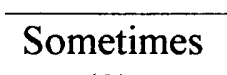

(2)

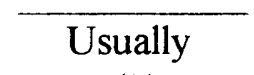

(3)
Always

(4)

\section{Kicking}


34. Other (please state type of response)

\begin{tabular}{|c|c|c|c|}
\hline $\begin{array}{l}\text { Never } \\
(0)\end{array}$ & $\begin{array}{l}\text { Rarely } \\
\text { (1) }\end{array}$ & $\begin{array}{l}\text { Sometimes } \\
\text { (2) }\end{array}$ & $\begin{array}{c}\text { Usually } \\
\text { (3) }\end{array}$ \\
\hline
\end{tabular}

Thank you for completing this questionnaire. I will share with you the results of this study when completed. Your participation will help in the development of an assessment tool for newborn pain. 
Appendix 5

Graduate Studies Bulletin

Announcement

Florida International University
Division of Graduate Studies

Master's Thesis Defense

\begin{abstract}
INCREASING NURSES' KNOWLEDGE OF NEONATAL PAIN

ASSESSMENT THROUGH INSERVICE EDUCATION PROGRAM.
\end{abstract}

by

Carol Beloff

Recognizing neonatal pain is a challenge for nurses working with newborns due to the complexity of the pain phenomenon. Pain is subjective, and infants lack the ability to communicate, and their pain is difficult to recognize. The purpose of this study is to determine the effectiveness of education on the NICU nurses' ability to assess neonatal pain. With a better understanding of pain theory and the effects of pain on the newborn the nurse will be better able to assess newborns with pain. Designed as a quasi-experimental one-group pretest and posttest study, the data was collected on a convenience sample of 49 registered nurses employed in the neonatal and special care nursery units at a Children's Hospital in the Miami area. The nurses were surveyed on the assessment of neonatal pain using the General Information and Pain Sensitivity Questionnaire. After the initial survey, the nurses were inserviced on neonatal pain assessment using a one hour inservice education program. One week after the intervention the nurse was asked to complete the questionnaire again. Data analysis involved comparison of pre and post intervention findings using descriptive methods, t-test, correlation coefficients, and ANOVA, where applicable. Findings revealed a significant $(\mathrm{p}=.006)$ increase in nurse's knowledge of neonatal pain assessment after completing the educational inservice when comparing the pre-test and post-test results.

Date: December 8, 1994

Department: Nursing

Time: $\quad 11: 00 \mathrm{AM}$

Major Professor: Dr. Luz S. Porter

Place: Dean's Conference Room

School of Nursing

North Miami Campus 